\title{
Erektil Disfonksiyon Hastalarına Multidisipliner Yaklaşım Gerekir mi?
}

\author{
Önder ÇİNAR ${ }^{1} \oplus \bowtie$, Mustafa Suat BOLAT ${ }^{2} \odot$ \\ ${ }^{1}$ Zonguldak Bülent Ecevit Üniversitesi, Tip Fakültesi, Üroloji Anabilim Dalı, Zonguldak, Türkiye \\ ${ }^{2}$ Samsun Gazi Devlet Hastanesi, Üroloji Kliniği, Samsun, Türkiye \\ Bu makaleye yapılacak atıf: Çinar Ö, Bolat MS. Erektil Disfonksiyon Hastalarına Multidisipliner Yaklaşım Gerekir mi?. Türk Diyab Obez 2020;3: 239-243.
}

ÖZ

Amaç: Hormonal, metabolik ve demografik değişkenlerin erkek cinsel sağlığı üzerine etkilerini araştırmak ve varsa bu ilişkileri multidisipliner çerçevede tartı̧maktır.

Gereç ve Yöntemler: Zonguldak Bülent Ecevit Üniversitesi ve Samsun Gazi Devlet Hastanesi Üroloji kliniklerine cinsel işlev bozuklukları nedeniyle başvuran 286 erkek hastanın ve sağlıklı 49 katılımcının erektil fonksiyonları ile ortalama yaş, vücut kütle indeksi (VKİ), ek hastalıkları, kullandıkları ilaçlar, sigara içme süresi, alkol alışkanlıkları kaydedildi. Toplam 335 katılımcının erektil fonksiyonları Uluslararası Erektil Fonksiyon İndeksi (IIEF 1-5,15) kullanılarak Kategori-1 (Normal), Kategori-2 (Hafif erektil disfonksiyon (ED)), Kategori-3 (Hafif-orta ED), Kategori-4 (Orta ED), Kategori-5 (Şiddetli (ED)) olarak 5 kategoride sınıflandırıldı. Katılımcılar; ED olmayanlar grup A $(n=49)$ ve olanlar grup B $(n=286)$ olarak gruplandırıldı. Grup B'de yer alan hastalardan hafif ve hafif-orta şiddette ED'u olanlar Grup BI ( $n=140)$, orta ve şiddetli derecede ED'u olan hastalar ise Grup BII ( $n=146)$ olarak gruplandırıldı. Her bir kategorideki olguların demografik, hormonal ve metabolik özellikleri istatistiksel olarak hesaplandı ve gruplar kategorik olarak karşılaştırıldı.

Bulgular: Grup A ve grup B'de yer alan hastaların yaş ortalamaları sırasıyla $50,2 \pm 8,6$ ve $52,3 \pm 10,1$ yld 1 ( $\mathrm{p}=0,185)$. Grup A ve grup B'de ortalama VKİ değerleri sırasıyla $26,7 \mathrm{ve} 28,4 \mathrm{~kg} / \mathrm{m}^{2}$, göbek çevresi $100 \mathrm{~cm}$ ve $103 \mathrm{~cm}(\mathrm{p}=0,020)$ (Tablo 1). Grup A ve B'de diyabetes mellitus prevalansı \%6,1 ve \%20,6 bulundu ( $\mathrm{p}=0,001)$. Grup BI'in yaş ortalaması ve VKİ değerleri sırasıly $51,5 \pm 10,9$ yll ve $28,2 \pm 4,2$ $\mathrm{kg} / \mathrm{m}^{2}$, grup BII'nin $53,1 \pm 9,3$ yll ve $29,0 \pm 3,9 \mathrm{~kg} / \mathrm{m}^{2}$ olarak hesaplandı ( $\left.\mathrm{p}>0,05\right)$. Grup BI ve BII'de yer alan hastaların ortalama göbek çevreleri sirasıyla $101,1 \pm 10,9 \mathrm{~cm}$ ve $105,5 \pm 11,0 \mathrm{~cm}$ olarak hesapland $(\mathrm{p}=0,001)$.

Sonuç: Androloji polikliniğine erektil disfonksiyon nedeniyle başvuran hastalar, özellikle diyabet, hipertansiyon, obezite gibi komorbiditeleri bakımından multidisipliner yaklaşımla değerlendirilmeli, bu olgular eşgüdümle takip ve tedavi edilmelidir.

Anahtar Sözciukler: Diyabet, Erektil disfonksiyon, Komorbidite, Multidisipliner yaklaşım, Obezite

\section{Is Multidisciplinary Approach Necessary to Erectile Dysfunction Patients?}

\begin{abstract}
Aim: To investigate the effects of hormonal, metabolic and demographic variables on male sexual health and to discuss these relationships in a multidisciplinary context.

Material and Methods: Erectile function, mean age, body mass index (BMI), comorbidities, medications, smoking and alcohol use of 286 male patients and 49 healthy participants who were admitted to the andrology clinics of Zonguldak Bulent Ecevit University and Samsun Gazi State Hospital were recorded. The erectile functions of a total of 335 participants were classified into 5 categories as; Category-1 (Normal), Category-2 (Mild), Category-3 (Mild-moderate), Category-4 (Moderate), Category-5 (Severe) erectile function using the International Index of Erectile Function (IIEF 1-5,15). Participants were grouped as; non-ED group, group A ( $n=49$ ) and ED group as, group B $(n=286)$. Patients in Group B with mild and moderate ED were grouped as Group BI $(n=140)$, and those with moderate and severe ED were grouped as Group BII $(n=146)$. The demographic, hormonal and metabolic characteristics of the cases in each category were statistically calculated and the groups were compared categorically.
\end{abstract}

ORCID: Önder Çinar / 0000-0002-0107-5843, Mustafa Suat Bolat / 0000-0002-4650-2271 
Results: The mean age of the patients in group A and group B were $50.2 \pm 8.6$ and $52.3 \pm 10.1$ years, respectively (p=0.185). In group A and group B, mean BMI values were 26.7 and $28.4 \mathrm{~kg} / \mathrm{m}^{2}$, belly circumference $100 \mathrm{~cm}$ and $103.3 \mathrm{~cm}$ (Table 1). The prevalence of diabetes mellitus in Group A and B was 6.1\% and 20.6\% ( $\mathrm{p}=0.001$ ). Mean age and BMI values of group BI were $51.5 \pm 10.9$ years and $28.2 \pm 4.2$ $\mathrm{kg} / \mathrm{m}^{2}$, while it was calculated as $53.1 \pm 9.3$ years and $29.0 \pm 3.9 \mathrm{~kg} / \mathrm{m}^{2}$, respectively, in group BII. The mean umbilical circumference of the patients in groups BI and BII was calculated as $101.1 \pm 10.9 \mathrm{~cm}$ and $105.5 \pm 11.0 \mathrm{~cm}$, respectively $(\mathrm{p}=0.001)$.

Conclusion: Patients who apply to the andrology outpatient clinic with erectile dysfunction should be evaluated especially in terms of comorbidities such as diabetes, hypertension and obesity, and cases with coexistence should be treated with a multidisciplinary approach.

Key Words: Diabetes, Erectile dysfunction, Comorbidity, Multidisciplinary treatment, Obesity

\section{GİRİş}

Erektil disfonksiyon (ED); organik ve/veya psikolojik etiyolojik faktörler nedeniyle, tatmin edici seksüel performans için gerekli olan düzeyde penil ereksiyonun gerçekleştirilememesi ve/veya sürdürülememesi olarak tanımlanır (1). ED nedenleri genel olarak vaskülojenik (arteryal ve venöz patolojiler), nörojenik, hormonal, iyatrojenik nedenler ve ilaçlar olarak sınıflandırılır. Penil ereksiyonun sağlıklı şekilde oluşabilmesi için endotelial nitrik oksitin yeterli düzeyde salgılanması ve kavernozal arterlerde vazodilatasyon gereklidir. Günümüzde sistemik endotel disfonksiyonunun bir göstergesi olarak kabul edilen ED, sadece cinsel aktiviteyi ilgilendiren bir sorun değil (2) aynı zamanda tedavi edilmediği takdirde kişinin yaşam süresini kısaltan koroner arter hastalığ $1(\mathrm{KAH})$ için de bir belirteç olarak kabul edilmektedir $(3,4)$. Yapılan çalışmalarda ED'nun başlangıcı ile kardiyovasküler olayın ortaya çıkışı arasında yaklaşık 3-5 yll olduğu gösterilmiştir $(5,6)$. ED için risk faktörleri olan sigara içilmesi, diyabet, hipertansiyon, obezite, dislipidemi varlığı aynı zamanda kardiovasküler hastalıklar için de risk faktörleri olarak bildirilmektedir (7-9). Özellikle 40 yaşın üstündeki erektil disfonksiyonu olan erkeklerde kardiyovasküler mortalitenin artmış olduğu; KAH'nı önlemek için yapılan egzersiz, vücut kütle endeksi (VKİ) azaltılması, yaşam tarzı değişiklikleri ve medikal tedavi kullanılmasının aynı zamanda cinsel fonksiyonları da iyileştirdiği gösterilmiştir (10-12).

$\mathrm{Bu}$ çalışmada, androloji polikliniklerine ED şikayetiyle başvuran hastaların hormonal, metabolik ve demografik değişkenlerinin kategorik olarak erektil fonksiyona etkileri retrospektif olarak araştırılmıştır.

\section{GEREÇ ve YÖNTEMLER}

Zonguldak Bülent Ecevit Üniversitesi Girişimsel Olmayan Klinik Araştırmalar Etik Kurulu'nun 04/11/2020 tarih ve 2020/21 sayılı onayı alındıktan sonra iki farklı merkezde androloji polikliniklerine ED nedeniyle başvuran 335 hastanın klinik verileri retrospektif olarak değerlendirildi. ED olmayan hastalar Grup A, olan hastalar ise Grup B olarak gruplandırıldı. Hastaların yaş, boy, kilo, VKİ, açlık kan şekeri ve testosteron düzeyleri, ek hastalıkları, kullandıkları ilaçları, sigara içme süreleri ve alkol alışkanlıkları kaydedildi. Hastaların erektil fonksiyonu, 6 sorudan oluşan Türkçe onaylı, kısa formda, Uluslararası Erektil Fonksiyon anketi (IIEF 1-5,15) kullanılarak değerlendirildi. Her soru 1'den (neredeyse hiç veya hiçbir zaman) 5'e (hemen hemen her zaman veya her zaman) kadar puanlandı ve toplam puanlar kaydedildi. Hastaların ED şiddeti; şiddetli ED (toplam puan $=0-6$ arasi), orta düzeyde ED (toplam puan $=7-12$ arası), hafif-orta düzeyde ED (toplam puan $=13-18$ arasi), hafif ED (toplam puan $=19-25$ arası) ve ED yok (toplam skor $=$ 26-30 aras1) olarak derecelendirildi (13).

\section{İstatistiksel Analiz}

Araştırma sonucunda elde edilen veriler, istatistiksel analiz SPSS 19.0 programı ile analiz edilmiştir. Çalışmada tanımlayıcı istatistiklerden; parametrik test varsayımları sağlandığı durumda sayısal değişkenler için ortalama \pm standart sapma sağlanmadığ 1 durumda medyan (minimum-maksimum) değerleri kullanılmıştır. Kategorik değişkenlere ait tanımlayıc1 istatistikler frekans ve yüzde ile belirtilmiştir. Sürekli değişkenlerin her grupta normal dağılıp dağılmadığı, hem görsel hem de olgu sayısı 50'nin altında iken Shapiro-Wilk, 50'nin üzerinde iken Kolmogorov-Smirnov normallik testiyle incelenmiştir. Normal dağılım gösteren değişkenlerin 2 grup karşılaştırmasında bağımsız örneklem $t$ testi, normal dağılım göstermeyen değişkenlerin 2 grup karşılaştırmasında Mann-Whitney U testi kullanılmıștır. İkiden çok grupta gruplar arası karşılaştırmada tek yönlü ANOVA ya da Kruskal-Wallis testi kullanılmıştır. Kategorik değişkenler içinse Ki-kare testi kullanılmıştır. Çalışmadaki tüm istatistiksel analizlerde, $p$ değeri için 0,05'in altındaki değerler istatistiksel olarak anlamlı kabul edilmiştir.

\section{BULGULAR}

Çalışmaya toplam 335 hasta dahil edildi. Hastalar ED şikayeti olmayan hastalar (Grup A, $n=49$ hasta) ve ED şikayeti olanlar (Grup B, n= 286 hasta) olarak ikiye ayrıldı. Ayrıca grup B'de yer alan hastalardan hafif ve hafif-orta şiddette 
ED olanlar Grup BI $(n=140)$, orta ve şiddetli derecede ED olan hastalar ise Grup BII $(n=146)$ olarak sinifland1rıld. Grup A ve grup B'de yer alan hastaların yaş ortalamaları sirasiyla $50,2 \pm 8,6$ ve $52,3 \pm 10,1$ yild $1(\mathrm{p}=0,185)$. Grup A ve grup B'de ortalama VKİ değerleri sırasıyla 26,7 ve $28,4 \mathrm{~kg} / \mathrm{m}^{2}$, göbek çevresi $100 \mathrm{~cm}$ ve $103 \mathrm{~cm}$ 'di ( $\mathrm{p}=0,006$ ve $\mathrm{p}=0,020$, sirasiyla) (Tablo 1 ). Grup A ve B'de diyabetes mellitus prevalansı $\% 6,1$ ve $\% 20,6$ bulundu ( $\mathrm{p}=0,001)$. Grup BI'in yaş ortalaması ve VKİ değerleri sırasıly $51,5 \pm 10,9$ yil ve $28,2 \pm 4,2 \mathrm{~kg} / \mathrm{m}^{2}$, grup BII'nin $53,1 \pm 9,3$ yll ve 29,0 $\pm 3,9 \mathrm{~kg} / \mathrm{m}^{2}$ olarak hesapland. Grup BI ve BII'de yer alan hastaların ortalama göbek çevreleri sırasıyla 101,1 $\pm 10,9 \mathrm{~cm}$ ve $105,5 \pm 11,0 \mathrm{~cm}$ olarak hesapland $(\mathrm{p}=0,001)$ (Tablo 2$)$.

\section{TARTIŞMA}

Tatmin edici seksüel performans için gerekli olan erektil fonksiyonun gerçekleşmemesi ya da sürdürülememesinin nedenleri çok değişkendir. İleri yaş, kardiyovasküler hastalıklar, diyabet, hipertansiyon, sigara kullanımı ile artmış ED insidansını gösteren çalışmalar, aynı zamanda bu risk faktörlerinin ED gelişmesinde en önemli tetikleyici mekanizma olan vasküler endotelial disfonksiyon üzerinden etki gösterdiklerini bildirmektedir (14-17). ED varlığı, arteryel sistemde ortaya çıkan aterosklerozun erken bir belirtisi olarak kabul edilmekte ve bu nedenle klinik olarak önem arzetmektedir (18). Vasküler endotelyal disfonksiyonun en önemli nedenlerinden biri olan diyabet (19) hastalarında ED prevalansında artış bildirilmiştir $(20,21)$. ED şikayetiyle başvuran hastaların ilk değerlendirmesinde \%12 oranında erektil disfonksiyon Tip-1 diyabetin ilk bulgusu olarak saptanmıştır (22). Diyabetik hastalarda artan ED riskinin, hem nörojenik hem de vaskülojenik kaynaklı olduğu düşünülmektedir (19). Çalışmamızda; grup B olgularının grup A'ya kıyasla ortalama VKİ, göbek çevresi ve diyabetes mellitus prevalansı daha yüksek bulundu. Grup BII olgularda beklendiği gibi diyabet hastalığının prevalansı daha yüksekdi. (Tablo-2). Tip 2 diyabet hastalarında göbek çevresinde ve VKİ'de artış ile birlikte ED ilişkisi bildirilmiştir. Bu bulgulara ek olarak çalışmamızda grup B olgularının ortalama trigliserid düzeyi daha yüksek saptandı. Ayrıca ED olan olgulardan grup BII'de yer alanlarda HT prevelansı daha yüksek saptandı. Tüm bu bulgular birlikte değerlendirildiğinde ED olan grup B'de VKİ artışı, göbek çevresindeki artış, diyabetes mellitus, hipertrigliseridemi ve HT preva-

Tablo 1: Çalışmaya katılan bireylerin demografik özellikleri.

\begin{tabular}{|c|c|c|c|}
\hline Demografik ve Klinik Özellikler & $\begin{array}{l}\text { Grup A } \\
(n=49)\end{array}$ & $\begin{array}{c}\text { Grup B } \\
(\mathrm{n}=286)\end{array}$ & $\mathbf{p}$ \\
\hline Yaş (yıl) (ort. \pm SS) & $50,2 \pm 8,6$ & $52,3 \pm 10,1$ & $0,185^{\mathrm{b}}$ \\
\hline VKİ $\left(\mathbf{k g} / \mathbf{m}^{2}\right)[\operatorname{ortanca}(\min -\max )]$ & $26,7(18-40)$ & $28,4(19,6-48,3)$ & $0,006^{\mathrm{a}}$ \\
\hline Sigara (paket / yll) [ortanca(min-max)] & $13,5(0-100)$ & $5(0-90)$ & $0,502^{\mathrm{a}}$ \\
\hline Düzenli alkol kullanımı (n) (\%) & $5(\% 10)$ & $28(\% 9)$ & $0,528^{c}$ \\
\hline Göbek Çevresi $(\mathrm{cm})[$ ortanca(min-max)] & $100(80-133)$ & $103(74-142)$ & $0,020^{\mathrm{a}}$ \\
\hline HT (n) (\%) & $7(14,2)$ & $68(23,8)$ & $0,117^{\mathrm{c}}$ \\
\hline DM (n) (\%) & $3(6,1)$ & $59(20,6)$ & $0,001^{\mathrm{c}}$ \\
\hline KAH (n) (\%) & $3(6,1)$ & $28(9,8)$ & $0,323^{\mathrm{c}}$ \\
\hline Açlık Kan Glikozu (mg/dL) [ortanca (min-max)] & $93(72-179)$ & $97(69-573)$ & $0,114^{\mathrm{a}}$ \\
\hline Testosteron (ng / dL) (ort. \pm SS) & $199,6 \pm 221,2$ & $191,4 \pm 231,7$ & $0,781^{\mathrm{b}}$ \\
\hline HDL (mg / dL) [ortanca (min-max)] & $49(29,8-201)$ & $43,6(23-223)$ & $0,247^{\mathrm{a}}$ \\
\hline Trigliserid (mg / dL) (ort. \pm SS) & $137,1 \pm 62,3$ & $187,4 \pm 113,8$ & $0,043^{b}$ \\
\hline ED süresi (ay) [ortanca(min-max)] & - & $6(1-280)$ & - \\
\hline ED şiddeti (IIEF skoru) (n) & & & - \\
\hline Hafif ED (19-25) (n) (\%) & - & $62(\% 18,5)$ & - \\
\hline Hafif-orta ED (13-18) (n) (\%) & - & $78(\% 23,3)$ & - \\
\hline Orta ED (7-12) (n) (\%) & - & $70(\% 20,9)$ & - \\
\hline Şiddetli ED (0-6) (n) (\%) & - & $76(\% 22,7)$ & - \\
\hline
\end{tabular}

Ort; Ortalama, SS; Standart sapma VKİ; Vücut kütle indeksi, HT; Hipertansiyon, DM; Diyabetes Mellitus, KAH; Koroner arter hastalı̆̆1, HDL; Yüksek dansiteli lipoprotein, ED; Erektil disfonksiyon, IIEF; Uluslararası erektil fonksiyon anketi. ${ }^{a}:$ Mann-Whitney U test kullanılmıştır ${ }^{\text {b}}$ : Independent Sample T test kullanılmışı̆ır ${ }^{c}$ : ki-kare testi uygulanmıştır. 
Tablo 2: Erektil disfonsiyonu olan grup BI ve grup BII hastaların karşılaştırılması.

\begin{tabular}{|c|c|c|c|}
\hline Parametreler & $\begin{array}{l}\text { Grup BI } \\
(n=140)\end{array}$ & $\begin{array}{l}\text { Grup BII } \\
(n=146)\end{array}$ & $\mathbf{p}$ \\
\hline Yaş (yıl) (ort. \pm SS) & $51,5 \pm 10,9$ & $53,1 \pm 9,3$ & $0,177^{\mathrm{b}}$ \\
\hline VKİ $\left(\mathrm{kg} / \mathrm{m}^{2}\right)($ ort. $\pm \mathrm{SS})$ & $28,2 \pm 4,2$ & $29,0 \pm 3,9$ & $0,113^{\mathrm{b}}$ \\
\hline Sigara (paket / yll) (ort. \pm SS) & $13,1 \pm 16,5$ & $16,7 \pm 17,8$ & $0,080^{\mathrm{b}}$ \\
\hline Göbek Çevresi (cm) (ort. \pm SS) & $101,1 \pm 10,9$ & $105,5 \pm 11,0$ & $\mathbf{0 , 0 0 1}^{\mathrm{b}}$ \\
\hline HT (n) (\%) & $24(\% 17,1)$ & $44(\% 30,1)$ & $\mathbf{0 , 0 3 3}{ }^{\mathrm{a}}$ \\
\hline DM (n) (\%) & $14(\% 10)$ & $45(\% 30,8)$ & $<0,001^{\text {a }}$ \\
\hline KAH (n) (\%) & $11(\% 7,9)$ & $17(\% 11,6)$ & $0,092^{\mathrm{a}}$ \\
\hline Açlık Kan Glikozu (mg/dL) (ort. \pm SS) & $116,4 \pm 62,6$ & $108,7 \pm 65,7$ & $0,313^{b}$ \\
\hline Testosteron (ng / dL) (ort. \pm SS) & $195,7 \pm 250,9$ & $182,5 \pm 205,2$ & $0,621^{\mathrm{b}}$ \\
\hline HDL (mg / dL) (ort. \pm SS) & $51,7 \pm 31,3$ & $44,1 \pm 8,4$ & $\mathbf{0 , 0 0 5}{ }^{\mathrm{b}}$ \\
\hline Trigliserid (mg / dL) (ort. \pm SS) & $175,6 \pm 105,5$ & $199,4 \pm 120,3$ & $0,072^{\mathrm{b}}$ \\
\hline ED süresi (ay) (ort. \pm SS) & $13,0 \pm 26,6$ & $34,2 \pm 69,9$ & $\mathbf{0 , 0 0 1}^{\mathrm{b}}$ \\
\hline
\end{tabular}

Ort; Ortalama, SS; Standart sapma VKİ; Vücut kütle indeksi, HT; Hipertansiyon, DM; Diyabetes Mellitus, KAH; Koroner arter hastalığ1, HDL; Yüksek dansiteli lipoprotein, ED; Erektil disfonksiyon, IIEF; Uluslararası erektil fonksiyon anketi. a : ki-kare testi uygulanmıştır b: Student-t testi uygulanmıştır.

lansında artış, ED şikayetiyle başvuran hastaların metabolik sendrom ve risk faktörleri bakımından dikkatli değerlendirilmesi gerektiğini düşündürmektedir.

Erektil disfonksiyon hastalarında $\mathrm{KAH}$, diyabet, obezite, hiperlipidemi varlığ 1 ve sigara öyküsü aterosklerozu başlatan ve hızlandıran faktörlerdendir $(23,24)$. ED tedavi edilmediği takdirde kişinin yaşam süresini kısaltan $\mathrm{KAH}$ ve diyabet gibi hastalıklar için erken bir uyarıcı belirteç olarak kabul edilmektedir $(3,4)$. Ayrıca; ED gelişimini takip eden 5 yıl içerisinde kardiyovasküler hastalık görülme riskinin arttığı, ED ve kardiyovasküler hastalığın ciddiyetinin orantılı olduğu bildirilmiş̧tir (25). Çalışmamızda; ED olan hastaların \%9,8'sinde KAH mevcuttu ve bu bakımdan grup A ve grup B hastalar arasında istatistiksel anlamlı farklılık saptanmadi. Ancak; erektil fonksiyonun derecelendirilmesinde kullanılan IIEF anketinde düşük skor elde eden hastalarda iki veya daha fazla komorbiditenin varlığı, ED’a neden olan mekanizmaların etkileşimi hakkındaki teorileri desteklemektedir (26). Ek olarak; KAH riskini azaltmak için önerilen; egzersiz, kilo verilmesi, yaşam tarzı değişiklikleri ve medikal tedavi kullanımının aynı zamanda erektil fonksiyonun iyileşmesine katkı sağladığı bildirilmiştir (10-12). Miyokard infarktüsü geçirmiş olan ve sonrasında fosfodiesteraz tip 5 inhibitörleri (PDE-5i) ile ED tedavisi gören hastalarda daha düşük ölüm oranı ve ilerleyen dönemde kalp yetmezliği nedeniyle daha az hastaneye yatış saptanmıştır (27). Yapılan metaanalizde ED tedavisinde kullanılan PDE-5i’nin kardiyak inotropizmi iyileştirdiği gösterilmiş- tir (28). Bu nedenlerle ED şikayetiyle başvuran erkeklerde, özellikle yaşam beklentisi uzun olan hastalarda, beraberinde KAH risk faktörleri de varsa kardiyoloji görüşünün alınması hastanın hem yaşam süresine ve yaşam kalitesine hem de erektil fonksiyonuna katkı sağlayacaktır.

Androloji polikliniklerine erektil disfonksiyon nedeniyle başvuran hastalar, özellikle diyabet, hipertansiyon, obezite gibi komorbiditeleri bakımından dikkatlice değerlendirilmeli ve birliktelik saptanan olgular multidisipliner yaklaşımla tedavi edilmelidir. ED olan olgularda; komorbiditeler için uygulanan tedavilerin hastanın erektil fonksiyonuna olan etkilerini araştırmak amacıyla uzun dönem, randomize, prospektif, geniş katılımlı çalışmalar gerekmektedir.

Etik Kurul Onayı

Zonguldak Bülent Ecevit Üniversitesi Girişimsel Olmayan Klinik Araştırmalar Etik Kurulu'nun 04/11/2020 tarih ve 2020/21 sayılı onayı alındı.

Çıkar Çatışması

Çıkar çatışması yoktur.

Finansal Destek

Finansal bir destek alınmamıștır.

Yazarların Makaleye Katkı Beyanı

Yazarlar eşit katkıda bulunmuştur.

Hakem Değerlendirmesi

Kör hakemlik süreci sonrası yayınlanmaya uygun bulunmuş ve kabul edilmiştir. 


\section{KAYNAKLAR}

1. NIH Consensus Conference. Impotence. NIH consensus development panel on impotence. JAMA. 1993;270(1):83-90.

2. Virag R, Zwang G, Dermange H, Legman M. Vasculogenic impotence: A review of 92 cases with 54 surgical operations. Vasc Surg. 1981;15:9-17.

3. Saigal CS, Wessells H, Pace J, Schonlau M, Wilt TJ. Urologic Diseases in America project. Predictors and prevalence of erectile dysfunction in a racially diverse population. Arch Intern Med. 2006;166(2):207-212.

4. Bacon CG, Mittleman MA, Kawachi I, Giovannucci E, Glasser DB, Rimm EB. A prospective study of risk factors for erectile dysfunction. J Urol. 2006;176(1):217-221.

5. Sai Ravi Shanker A, Phanikrishna B, Bhaktha Vatsala Reddy C. Association between erectile dysfunction and coronary artery disease and its severity. Indian Heart J. 2013;65(2):180-186.

6. Montorsi P, Ravagnani PM, Galli S, Rotatori F, Veglia F, Briganti A, Salonia A, Dehò F, Rigatti P, Montorsi F, Fiorentini C. Association between erectile dysfunction and coronary artery disease. Role of coronary clinical presentation and extent of coronary vessels involvement: the COBRA trial. Eur Heart J. 2006;27(22):2632-2639.

7. Baumhäkel M, Schlimmer N, Kratz M, Hackett G, Jackson G, Böhm M. Cardiovascular risk, drugs and erectile function-a systematic analysis. Int J Clin Pract. 2011;65(3):289-298.

8. Guo W, Liao C, Zou Y, Li F, Li T, Zhou Q, Cao Y, Mao X. Erectile dysfunction and risk of clinical cardiovascular events: A meta-analysis of seven cohort studies. J Sex Med. 2010;7(8):2805-2816.

9. Jackson G, Boon N, Eardley I, Kirby M, Dean J, Hackett G, Montorsi P, Montorsi F, Vlachopoulos C, Kloner R, Sharlip I, Miner M. Erectile dysfunction and coronary artery disease prediction: Evidence-based guidance and consensus. Int J Clin Pract. 2010;64(7):848-857.

10. Gandaglia G, Briganti A, Jackson G, Kloner RA, Montorsi F, Montorsi P, Vlachopoulos C. A systematic review of the association between erectile dysfunction and cardiovascular disease. Eur Urol. 2014;65(5):968-978.

11. Glina S, Sharlip ID, Hellstrom WJ. Modifying risk factors to prevent and treat erectile dysfunction. J Sex Med. 2013;10(1):115-119.

12. Vlachopoulos C, Jackson G, Stefanadis C, Montorsi P. Erectile dysfunction in the cardiovascular patient. Eur Heart J. 2013;34(27):2034-2046.

13. Turunç T, Deveci S, Güvel S, Peşkircioğlu L. The assessment of Turkish validation with 5 question version of International Index of Erectile Function (IIEF-5). Turk J Urol. 2007;33:45-49.

14. Feldman HA, Goldstein I, Hatzichristou DG, Krane RJ, McKinlay JB. Impotence and its medical and psychosocial correlates: Results of the massachusetts male aging study. J Urol. 1994;151(1):54-61.

15. Goldstein I, McCullough AR, Jones LA, Hellstrom WJ, Bowden CH, Didonato K, Trask B, Day WW. A randomized, double-blind, placebo-controlled evaluation of the safety and efficacy of avanafil in subjects with erectile dysfunction. J Sex Med. 2012;9(4):1122-1133.
16. Johannes CB, Araujo AB, Feldman HA, Derby CA, Kleinman $\mathrm{KP}, \mathrm{McKinlay}$ JB. Incidence of erectile dysfunction in men 40 to 69 years old: Longitudinal results from the Massachusetts male aging study. J Urol. 2000;163(2):460-463.

17. Selvin E, Burnett AL, Platz EA. Prevalence and risk factors for erectile dysfunction in the US. The American Journal of. Medicine. 2007;120(2):151-157.

18. Thompson IM, Tangen CM, Goodman PJ, Probstfield JL, Moinpour CM, Coltman CA. Erectile dysfunction and subsequent cardiovascular disease. JAMA. 2005 21;294(23):2996-3002.

19. Pegge NC, Twomey AM, Vaughton K, Gravenor MB, Ramsey MW, Price DE. The role of endothelial dysfunction in the pathophysiology of erectile dysfunction in diabetes and in determining response to treatment. Diabet Med. 2006;23(8):873-878.

20. Kouidrat Y, Pizzol D, Cosco T, Thompson T, Carnaghi M, Bertoldo A, Solmi M, Stubbs B, Veronese N. High prevalence of erectile dysfunction in diabetes: A systematic review and meta-analysis of 145 studies. Diabet Med. 2017;34(9):11851192.

21. Bolat MS, Cinar O, Akdeniz E, Așcı R. Low dose daily versus on-demand high dose tadalafil in diabetic patients with erectile and ejaculatory dysfunction. Int J Impot Res. 2018;30(3):102107.

22. Gratzke C, Angulo J, Chitaley K, Dai Y-t, Kim NN, Paick JS, Simonsen U, Ückert S, Wespes E, Andersson KE, Lue TF, Stief CG. Anatomy, physiology, and pathophysiology of erectile dysfunction. The Journal of Sexual Medicine. 2010;7:445-475.

23. El-Sakka AI, Morsy AM. Screening for ischemic heart disease in patients with erectile dysfunction: Role of penile Doppler ultrasonography. Urology. 2004;64(2):346-350.

24. Shamloul R, Ghanem H. Erectile dysfunction. Lancet. 2013;381(9861):153-165.

25. Hannan JL, Maio MT, Komolova M, Adams MA. Beneficial impact of exercise and obesity interventions on erectile function and its risk factors. J Sex Med. 2009;6(Suppl 3):254261.

26. Meller SM, Stilp E, Walker CN, Mena-Hurtado C. The link between vasculogenic erectile dysfunction, coronary artery disease, and peripheral artery disease: Role of metabolic factors and endovascular therapy. J Invasive Cardiol. 2013;25(6):313319.

27. Andersson DP, Trolle Lagerros Y, Grotta A, Bellocco R, Lehtihet M, Holzmann MJ. Association between treatment for erectile dysfunction and death or cardiovascular outcomes after myocardial infarction. Heart. 2017;103(16):1264-1270.

28. Giannetta E, Feola T, Gianfrilli D, Pofi R, Dall'Armi V, Badagliacca R, Barbagallo F, Lenzi A, Isidori AM. Is chronic inhibition of phosphodiesterase type 5 cardioprotective and safe? A meta-analysis of randomized controlled trials. BMC Med. 2014;12:185. 